\title{
Public Knowledge about Causes of Cancer and Possibilities for Prevention and Early Diagnosis of Cancer Diseases
}

\author{
VF Levshin* and VV Surin \\ N.N. Blokhin National Medical Research Center of Oncology, Russia
}

*Corresponding author: Levshin Vladimir Filippovich, N.N. Blokhin National Medical Research Center of Oncology, Russia

\section{ARTICLE INFO}

Received: March 13, 2021

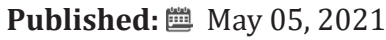

Citation: VF Levshin, VV Surin. Public Knowledge about Causes of Cancer and Possibilities for Prevention and Early Diagnosis of Cancer Diseases. Biomed J Sci \& Tech Res 35(4)-2021. BJSTR. MS.ID.005725.

Keywords: Cancer Prevention; Risk Factors; Public Cancer Knowledge; Health Education

\begin{abstract}
Objective: The aim of this study was to evaluate awarnness of cancer risk factors and measure of cancer prevention among healthy Moscow residence.

Material and Methods: A cross-sectional study was conducted at Moscow, with survey of the random sample of Moscow adult residence. Adult persons were recruited in municipal out-patient clinics in Moscow, where they were invited to take part in semistructured telephone interviews. A total 235 persons, aged 20 - 79 years, were the subject of the study. The median age is 51, the number of women in the study sample was 165 (70\%), men - $70(30 \%)$. Data were collected by personal formalized interviews using the unified and structured questionnaire which included questions about the following personal characteristics: gender, age, education, lifestyle and bad habits; medical history and knowledge about the causes of cancer, cancer prevention measures and early diagnosis methods. Statistical analysis of data was carried out by methods of descriptive statistics, and single-factor dispersion analysis. The categorical variables are described as relative frequencies (\%) and 95\% confidence intervals (95\% CI).
\end{abstract}

Results: According to the results of the survey, 42\% (95\% CI: 35.7, 48.3) of the respondents knew nothing or had the wrong knowledge about the causes of cancer, $49 \%$ of the respondents had insufficient knowledge and $9 \%$ of the respondents had sufficient knowledge. About the possibilities and measures of cancer prevention 48.4\% (95\% CI: $42.7,55.4$ ) of the respondents knew nothing or had the wrong knowledge, $45.3 \%$ - had insufficient knowledge and 6.3\% - had sufficient knowledge. About the methods of early diagnosis of cancer $73.8 \%$ (95\% CI: 68.6, 79.4) of the respondents knew nothing or had the wrong knowledge, $23 \%$ - had insufficient knowledge and only $3.2 \%$ - had sufficient knowledge. There was a slightly higher awareness of the causes and measures of cancer prevention among women compared to men, and in the 40-59 age group, than in the younger and older age groups.

Conclusion: The apparent lack of knowledge about cancer prevention among the population, established in this study, suggests the need for active public education on the subject, using available types and channels of information. The most effective individualized evidence-based education with personal recommendations on cancer prevention, carried out by health professional. Knowledge could help to avoid risk factors and motivate prevention behavior. Timely prevention at the primary health care level is the most important area of action to reduce cancer incidence.

\section{Introduction}

Cancer is the second leading cause of death in many countries around the world, including Russia. However, while mortality from a number of forms of cancer has been reduced in the last several decades, due to improved treatments and early cancer diagnosis, the incidence continues to increase worldwide [1,2]. It is possible to stop the increase in cancer morbidity and reduce 
it only by measures and methods of cancer prevention. Methods and technologies for preventing various forms of cancer have now been developed based on the study of the causes and risk factors of cancer. Cancer prevention is carried out by eliminating or controlling the scientifically proven and potentially modifiable causes and risk factors of this disease [3]. There are estimates that up to $70 \%$ of all cancers are causally related to environmental and lifestyle factors [4]. The major modifiable risk factors for cancer are active and passive smoking, overweight and obesity, alcohol abuse, insufficient consumption of vegetables, fruits and greens, dietary fiber and calcium, lack of physical activity, increased ultraviolet radiation; 5 types of infections classified as carcinogenic to humans.

Successful elimination of these factors or the neutralization of their action can prevent $30-50 \%$ of all expected cancer cases in the population [4]. But full potential of preventive strategy is still far from being realized and remains at an early stage [2]. In implementing preventive measures and realizing their ability to prevent the development of cancer, the main role is not in health workers, but in the persons themselves. At the same time, their behavior, implementation of preventive measures and adherence to the doctor's preventive recommendations is determined, first of all, by the level of knowledge about the causes of cancer and measures to prevent them. In particularly knowledge about cancer risk factors was identified as an important variable that affects person's avoidance risk factors of cancer [5]. Therefore, lack of public awareness of the possibilities and methods of cancer prevention can be a major barrier for cancer prevention and reducing the incidence.

\section{Material and Methods}

The aim of this study was to evaluate awarnness of cancer risk factors and measure of cancer prevention among healthy Moscow residence. A cross-sectional study was conducted at Moscow, with survey of the random sample of Moscow adult residence. Adult persons were recruited in municipal out-patient clinics in Moscow, where they were invited to take part in semi-structured telephone interviews. A total of 280 persons were invited to be interviewed, 235 (84\%) persons agreed to it and $45(16 \%)$ persons refused for various reasons. Thus, 235 persons, aged 20 - 79 years, were the subject of the study. The median age is 51 , the number of women in the study sample was 165 (70\%), men - 70 (30\%). Data were collected by trained interviewers through personal formalized interviews using a unified and structured questionnaire which included questions about the following personal characteristics: gender, age, education, lifestyle and bad habits; medical history and knowledge about the causes of cancer, cancer prevention measures and early diagnosis methods.

To assess medical literacy and participants awareness of the possibilities and measures of cancer prevention, the questionnaire included the following questions:

a) What do you know about the causes of tumor disease?

b) What do you know about the possibilities and measures of preventing tumor diseases?

c) What do you know about the methods of correct and early diagnosis of tumors?

Marks were attributed to answers on each question to evaluate a level of the personal relevant knowledge. Participants fell in four levels of knowledge:

1) Did not know (could not name anything);

2) Incorrect answers were given;

3) Not sufficient knowledge (only 1-2 causes or measures to prevent cancer were named);

4) Sufficient knowledge (named 3 or more causes or and measures to prevent cancer).

Statistical analysis of data was carried out by methods of descriptive statistics, and single-factor dispersion analysis. The categorical variables are described as relative frequencies (\%) and $95 \%$ confidence intervals $(95 \% \mathrm{CI})$.

\section{Results}

The results of the survey showed that, $42 \%$ (95\% CI: 35.7, 48.3) of the respondents knew nothing or had the wrong knowledge about the causes of cancer, around half, $49 \%$ of the respondents had insufficient knowledge and $9 \%$ of the respondents had sufficient knowledge. About the possibilities and measures of cancer prevention $48.4 \%$ (95\% CI: 42.7, 55.4) of the respondents knew nothing or had the wrong knowledge, $45.3 \%$ - had insufficient knowledge and $6.3 \%$ - had sufficient knowledge. About the methods of early diagnosis of cancer $73.8 \%$ (95\% CI: 68.6, 79.4) of the respondents knew nothing or had the wrong knowledge, $23 \%$ - had insufficient knowledge and only 3.2\% - had sufficient knowledge. There was a slightly higher awareness of the causes and measures of cancer prevention among women compared to men, and in the 40-59 age group, than in the younger and older age groups. Other variables, including employment status, educational level and medical history had no significant association with a level of relevant knowledge.

\section{Conclusion}

The results of the cross-sectional survey showed that the great majority of people surveyed in a random sample of the population did not know or had incorrect or insufficient knowledge about the causes of cancer and measures and methods of their prevention and early diagnosis. Relatively sufficient knowledge about the causes of cancer, prevention measures and methods of early 
diagnosis of cancer had only $9 \%, 6.3 \%$ and $3.2 \%$ of the interviewed persons, respectively. At the same time, people's awareness about the possibility of the prevention of most cancer cases and evidence-based measures of prevention is the main condition of the successful and effective implementation of prevention measures in people's lifestyles and in practical healthcare and for reducing cancer morbidity and mortality. The knowledge could help to avoid risk factors and motivate prevention behavior. The apparent lack of knowledge about cancer prevention among the population, established in this study, suggests the need for active public education on the subject, using available types and channels of information.

There are different forms of education for diseases prevention: population forms (articles and speech in mass-media with print and electronic forms), group forms (specialized schools, focus groups and classes for patients) and individual (recommendation at the doctor's appointment). All of these forms can be quite effective and all of them should be used. The most effective individualized evidence-based education with personal recommendations on cancer prevention, carried out by a doctor taking into account the lifestyle of a certain patient and assessing his personal risk of different forms of cancer. Timely prevention at the primary care level is one of the most important areas on which health professionals

\section{ISSN: 2574-1241}

DOI: 10.26717/BJSTR.2021.35.005725

VF Levshin. Biomed J Sci \& Tech Res

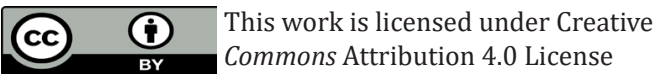

Submission Link: https://biomedres.us/submit-manuscript.php need to focus and to reduce the cancer incidence. Therefore, health professionals also need training on cancer risks factors, preventive measures and screening methods. Appropriate guidelines for GPs and family doctors should be prepared and distributed among them for cancer prevention to be widely introduced into practical health care.

\section{References}

1. Bray F, Ferlay J, Soerjomataram I, Siegel RL, Torre LA, et al. (2018) Global cancer statistics 2018: GLOBOCAN estimates of incidence and mortality worldwide for 36 cancers in 185 countries. CA Cancer J Clin 68(6): 394424 .

2. Krstic MN, Mijac DD, Popovic DD, Pavlovic Markovic A, Milosavljević T (2019) General Aspects of Primary Cancer Prevention. Dig Dis 37(5): 406-415.

3. Wang M, Pazaris M, Willett WC, Eliassen AH, Hunter DJ (2016) Population Attributable Risk of Modifiable and Nonmodifiable Breast Cancer Risk Factors in Postmenopausal Breast Cancer. Am J Epidemiol 184(12): 884893.

4. Kolak A, Kamińska M, Sygit K, Budny A, Surdyka D, et al. (2017) Primary and secondary prevention of breast cancer. Ann Agric Environ Med 24(4): 549-553.

5. Islami F, Goding Sauer A, Miller KD, Siegel RL, Fedewa SA, et al. (2018) Proportion and number of cancer cases and deaths attributable to potentially modifiable risk factors in the United States. CA Cancer J Clin 68(1): 31-54

$\begin{array}{ll}\text { BIOMEDICAL } & \text { Assets of Publishing with us } \\ \text { RESEARCHES } & \text { - Global archiving of articles } \\ \text { - Immediate, unrestricted online access } & \text { - Rigorous Peer Review Process } \\ & \text { - Authors Retain Copyrights } \\ \end{array}$

